\title{
Efficacy of Platelet Rich Plasma (PRP) Gel in Bone Regeneration of Periapical Cystic Lesion
}

\author{
Sonam Nankani ${ }^{1}$, Suneel Kumar Punjabi ${ }^{2}$, Naveen Khawaja ${ }^{3}$ and Salman Shams ${ }^{4 *}$ \\ ${ }^{1}$ Department of Oral Medicine, Dr Ishrat-Ul-Ebad Khan, Institute of Oral Health Sciences, Dow University of Health Sciences, \\ Karachi, Sindh, Pakistan
}

${ }^{2}$ Associate Professor, Oral \& Maxillofacial Surgery Department, Faculty of Dentistry, Liaquat University of Medical and Health Sciences, Pakistan

${ }^{3}$ MSc Lecturer, Oral \& Maxillofacial Surgery Department, Faculty of Dentistry, Liaquat University of Medical and Health Sciences, Pakistan

${ }^{4}$ Senior Lecturer, Department of Oral and Maxillofacial Surgery, Liaquat University of Medical and Health Sciences, Pakistan

\begin{abstract}
Objective: To evaluate the efficacy of Platelet rich plasma gel in bone regeneration of periapical cystic lesion.

Study Design: Experimental case series.

Place and Duration of Study: Oral \& Maxillofacial Surgery Department, Institute of Dentistry, Liaquat University of Medical \& Health Sciences, Jamshoro/ Hyderabad, from May 2017 to January 2018.

Methodology: Data was collected from Outpatient Department patients of Oral \& Maxillofacial Surgery Department, Liaquat University of Medical \& Health Sciences Jamshoro/Hyderabad who fulfilling the inclusion criteria. Root canal therapy of involved tooth. After that Blood sample of patient with help of 10cc disposable syringe and draw 10 ml blood intravenously. For 10 minutes blood sample was centrifuged and then Platelet rich plasma gel formed. After getting the gel is stable within anti-cogulated condition and stored as 8 hours at room temperature. With the help of 18-gauge needle Platelet rich plasma gel will subsequently introduced immediately into the bone cavity to fill up the empty space completely. Platelet-rich rich plasma (PRP) gel application and assessed the measurement on pre and post periapical radiograph that is with the help of ruler will recorded on proforma at $2^{\text {nd }}$ week, $4^{\text {th }}$ week, 12 weeks, and $24^{\text {th }}$ week
\end{abstract}

Results: The total number 45 patients were included in this study to treat the periapical cystic lesion with Platelet rich plasma gel for healing. Mean defect size was $3.88 \pm 1.25 \mathrm{~cm}$ after $1^{\text {st }}$ week it was observed $3.19 \pm 1.06 \mathrm{~cm}$ than at $4^{\text {th }}$ week followup it was $2.46 \pm 0.87 \mathrm{~cm}$ and at $12^{\text {th }}$ weeks defect size was $1.39 \pm 0.61 \mathrm{~cm}$ it was also reduced at $24^{\text {th }}$ week which was observed in $0.53 \pm 0.32 \mathrm{~cm}$. At 24 weeks mean defect done fill was $95.95 \pm 1.91 \%$ which is showing rapid healing.

Conclusion: The result of this study concluded that platelet rich plasma gel (PRP gel) was highly effective in healing of cystic bony defect resulting from enucleation of periapical cyst in speedy motion by clinically and radiographically.

KEYWORDS: Periapical cyst; Enucleation; Curettage; Platelet rich plasma gel

Quick Response Code:

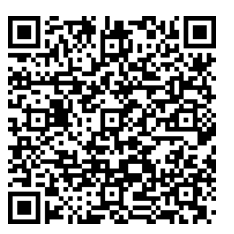

Address for correspondence: Salman Shams, BDS, MSc. Senior Lecturer, Department of Oral and Maxillofacial Surger, Liaquat University of Medical and Health Sciences, Pakistan

Received: June 08, 2020 Published: June 18, 2020

How to cite this article: Sonam N, Suneel Kumar P, Naveen K, Salman S. Efficacy of Platelet Rich Plasma (PRP) Gel in Bone Regeneration of Periapical Cystic Lesion. 2020 - 2(3) OAJBS.ID.000183. DOI: $10.38125 / \mathrm{OAJBS} .000183$ 


\section{INTRODUCTION}

Cyst could be a benign pathological cavity which will remain occupied by fluid, semi fluid or gaseous matters except pus and it is going to or might neither be covered with epithelium [1]. The expansion of cystic cavity is due to fluid collection and expression of various cytokines. However, this expansion can cause resorption of the bone. The buccal bone is more vulnerable and least resistance bone to resorp [2]. Cyst in the oral cavity is highly distinguished into odontogenic and non-odontogenic source along with developmental and inflammatory origin [3]. Odontogenic cyst is of true cysts arising from epithelium residual in tooth development [4]. Non odontogenic cysts originate from ectoderm covered in facial tissue development.

The most frequent odontogenic cyst of teeth bearing areas is the periapical cyst occurring approximately $62 \%$ of jaw cysts $[5,6]$. The periapical cyst of jaws is raised after stimulation of odontogenic epithelium through inflammation causing obliteration of periradicular tissues, loss of lamina dura along with development of radiolucent void in circular to ovoid shape $[7,8]$. Periapical cyst is generally described as a cyst originating from trauma within the tooth, epithelial residual or cell rests of malassez to the periodontal ligament during a result like pulpal infection arising from dental caries and periapical periodontitis resulting in destruction and necrosis of the pulp $[9,10]$. The endodontic bacteria are the most frequent etiologic factor for periapical cyst [7]. Periapical cyst is usually asymptomatic slow growing, sterile unless it is secondarily infected and diagnosed incidentally on radiograph. The affected tooth that are not responded to thermal and electrical pulp testing $[11,12]$. Periapical cysts are ranging from $1-5 \mathrm{~cm}$ in size [13].

According to the size and the location of the lesion's treatment can be conventional, non-surgical or surgical. The non-surgical approaches the extraction of causative tooth, and the surgical approaches are marsuplization or enucleation with or without curettage [14]. The postsurgical procedure involves two main factors regeneration and repair.13 Repair as biological modulators led to developing Platelet Rich Plasma via Whitmen et al15. Platelet concentrates designed for surgical utilize as devices from regenerative treatment methods used for the local discharge of platelet growth factors with in a surgical or wounded site. In 1998 Marx et al16. He found that it was a simple and less complicated procedure. Its use to improve the amount and extent of new bone formation [15]. That sticky gel made up of Platelet rich plasma (PRP) act as hemostatic factor and stabilize the blood clot. This gel also has a function as anti-inflammatory agent [16-18].

Platelet- rich plasma is a blood by-product which is initiated with different centrifuging platelets and these platelets are gathered into very little quantity of plasma amount. It is by-product of the patient's very own blood; therefore, the less possibilities of infection disease transmission. The origin of autologous platelet rich plasma for gaining growth factors particularly platelet derived growth factor and remodelling growth factor $\beta$ are required as for regeneration of bone [19]. This benefit from Platelet- rich plasma is speed up the new bone formation. It also improves the vascularity within initial 20 days with a new bone formation during osteoblastic activity and immature the osteoid tissue development within 3-6 weeks raising the condition and amount of bone tissue in a new made bone. Histomorphological considerations illustrated such patients treated through Platelet rich plasma obtained $100 \%$ bone regeneration within 24 weeks. This indicates that there's increase in rate of bone growth with platelet rich plasma [20]. Aim of this study was conducted to observe the rapid bone healing by application of platelet rich plasma gel in the bony defect of cystic cavity.

\section{METHODOLOGY}

Data were collected from Outpatient Department patients of Oral \& Maxillofacial Surgery Department, Liaquat University of Medical \& Health Sciences Jamshoro/Hyderabad were fulfilling the inclusion criteria. Before surgical procedure a written and informed consent was taken from the patient by researcher. Patient's complete history recorded on proforma that included patient's name, age, gender, presenting complaint, and clinical findings like site of cyst occurrence, with or without swelling, pus discharge, present or absent of tooth mobility/vitality, fluctuance and the aspiration of fluid with disposable syringe from cavity of cystic lesion was recorded. Radiological features of the cysts were seen OPG and peri-apical view $\mathrm{x}$-rays has been recorded. Radiographic features were recorded including size of cyst appeared, adjacent teeth root resorption and local anatomical structures association.

Clinically and radiologically after the diagnosis of periapical cyst the patient was referred to conservative department, Institute of Dentistry, Liaquat University of Medical \& Health Sciences, Jamshoro/Hyderabad for root canal treatment of affected tooth / teeth that was either with rotary or manual root canal were done by specialist of the department [21].

\section{PROCEDURE}

\section{Preparation of Platelet-Rich Plasma (PRP) Gel}

Firstly patient was referred to Diagnostic \& Research Laboratory Liaquat University of Medical \& Health Sciences Jamshoro/Hyderabad where the expert lab technician was drawn blood sample of patient with help of $10 \mathrm{cc}$ disposable syringe and draw $10 \mathrm{ml}$ blood intravenously from patient's antecubital vein and stored in coated tube of sterile plastic vacuum tube using a sodium citrate (anticoagulant). For 10 minutes blood sample was centrifuged with a speed of $1300 \mathrm{rpm}$ following in which layers were obtained: a upper layer of straw colour fluid, that was poor platelet plasma; a buffy coat in middle made from platelet-rich and; the lower layer of full RBCs. The plasma, buffy coat and $1 \mathrm{ml}$ of RBC layer were aspirated into another sterile tube with no anticoagulant. It was again centrifuged for 10 mins with speed of $2400 \mathrm{rpm}$, to separate the Platelet poor plasma from the Platelet rich plasma. This upper layer made from Platelet poor plasma was dumped and Platelet rich plasma stayed over on a tube based so within the form like a red button. For activation purpose, $6 \mathrm{ml}$ of calcium chloride and thrombin was added and a resultant Platelet rich plasma gel was formed after preparing the gel is stable within anticoagulated condition and stored as 8 hours at room temperature [22].

\section{Surgery}

A standard preparation with draping was done, the local anaesthesia of Xylocaine with adrenaline 2\% (Medicine; Made in Korea ) was given, using sterile surgical blade (feather safety razor co. Ltd Japan) make the incision whichever were suitable for every case and a full thickness mucoperiosteal flap was reflected and bony window prepared to access the lesion using rotary, long shank straight surgical round bur (Mani Japan). Complete enucleation, curettage if needed followed by copious irrigation with sterile normal saline solution 0.9\% (Searle Ltd. Pakistan). 10\% formalin neutral solution used for lesion histopathological examination and sample was sent to confirm the definitive diagnosis of periapical 
cyst. With the help of 18 gauge needle Platelet rich plasma gel will subsequently introduced immediately into the bone cavity to fill up the empty space completely and the observation of regenerated bone (defect bone fill) seen on patient as well as periapical radiograph with the help of ruler. Flap was repositioned and suture with resorable suture 3/0 vicryl (Johnson \& Jhonson; made in USA). Post-operative instruction was given, standard antibiotics (Tab: Augmentin 625mg BID) and analgesics (Tab: Brufen 400mg TID) prescribed for 5 days patient recall visits at interval of $3^{\text {rd }}$ and $7^{\text {th }}$ day, for routine intraoral and extra oral examination follow up for intra oral radiographs and record the cystic bone defect size along with healed bone (defect bone fill) using platelet-rich rich plasma (PRP) gel application and assessed the measurement on pre and post periapical radiograph that is with the help of ruler will recorded on proforma at $2^{\text {nd }}$ week, $4^{\text {th }}$ week, 12 weeks, and $24^{\text {th }}$ week were recommended to revealed healing process and bone regeneration.

All data has been input in statistical package to social service (SPSS) version 20.0 then analyzed. Mean with standard derivation were computed considering age, size of cyst, defect size and defect bone fills. Frequency and percentage were computed for gender, symptoms of radicular cyst, radiographic findings. Repeated measure ANOVA was applied to observe within subject effect and for multiple comparisons, Bonferroni test was used. P-value 0.05 less then were included as significant.

\section{RESULTS}

The patient's average age was $36.49 \pm 13.15$ years. Site regarding clinical findings of periapical cyst of the patients, pain was observed in $53.3 \%$ patients, swelling $100 \%$, mobility $48.9 \%$, resorption of root $40 \%$, displacement of adjacent teeth $24.4 \%$. Pus discharge was observed in $13.3 \%$ cases and color of aspirated fluid is also reported in Table 1. Mean size of cyst was $3.88 \pm 1.12 \mathrm{~cm}$ (Table 2).
Table 1: Clinical findings of periapicalcyst.

\begin{tabular}{|c|c|c|}
\hline Clinical Finding & Frequency & Percentage \\
\hline Pain & 24 & $53.30 \%$ \\
\hline Swelling & 45 & $100 \%$ \\
\hline Mobility & 22 & $48.90 \%$ \\
\hline Resorption of root & 18 & $40 \%$ \\
\hline $\begin{array}{c}\text { Displacement of } \\
\text { adjacent teeth }\end{array}$ & 11 & $24.40 \%$ \\
\hline \multicolumn{2}{|c|}{ Status of Tooth } \\
\hline Pus Discharge & 6 & $13.30 \%$ \\
\hline \multicolumn{2}{|c|}{ Color of the Aspirated Fluid } \\
\hline Straw Color & 20 & $44.40 \%$ \\
\hline Yellow Color & 19 & $42.20 \%$ \\
\hline Transparent & 6 & $13.30 \%$ \\
\hline
\end{tabular}

Table 2: Radiographical findings in term of size of syst.

\begin{tabular}{|c|c|c|}
\hline \multicolumn{2}{|c|}{ Descriptive Statistics } & Size of Cyst $(\mathrm{cm})$ \\
\hline \multicolumn{2}{|c|}{ Mean } & 3.88 \\
\hline \multicolumn{2}{|c|}{ Std. Deviation } & 1.12 \\
\hline \multirow[t]{2}{*}{$\begin{array}{l}\text { 95\% Confidence Interval } \\
\text { for Mean }\end{array}$} & Lower Bound & 3.55 \\
\hline & Upper Bound & 4.23 \\
\hline \multicolumn{2}{|c|}{ Median } & 4 \\
\hline \multicolumn{2}{|c|}{ Inter quartile Range } & 1.9 \\
\hline \multicolumn{2}{|c|}{ Minimum } & 2 \\
\hline \multicolumn{2}{|c|}{ Maximum } & 6 \\
\hline
\end{tabular}

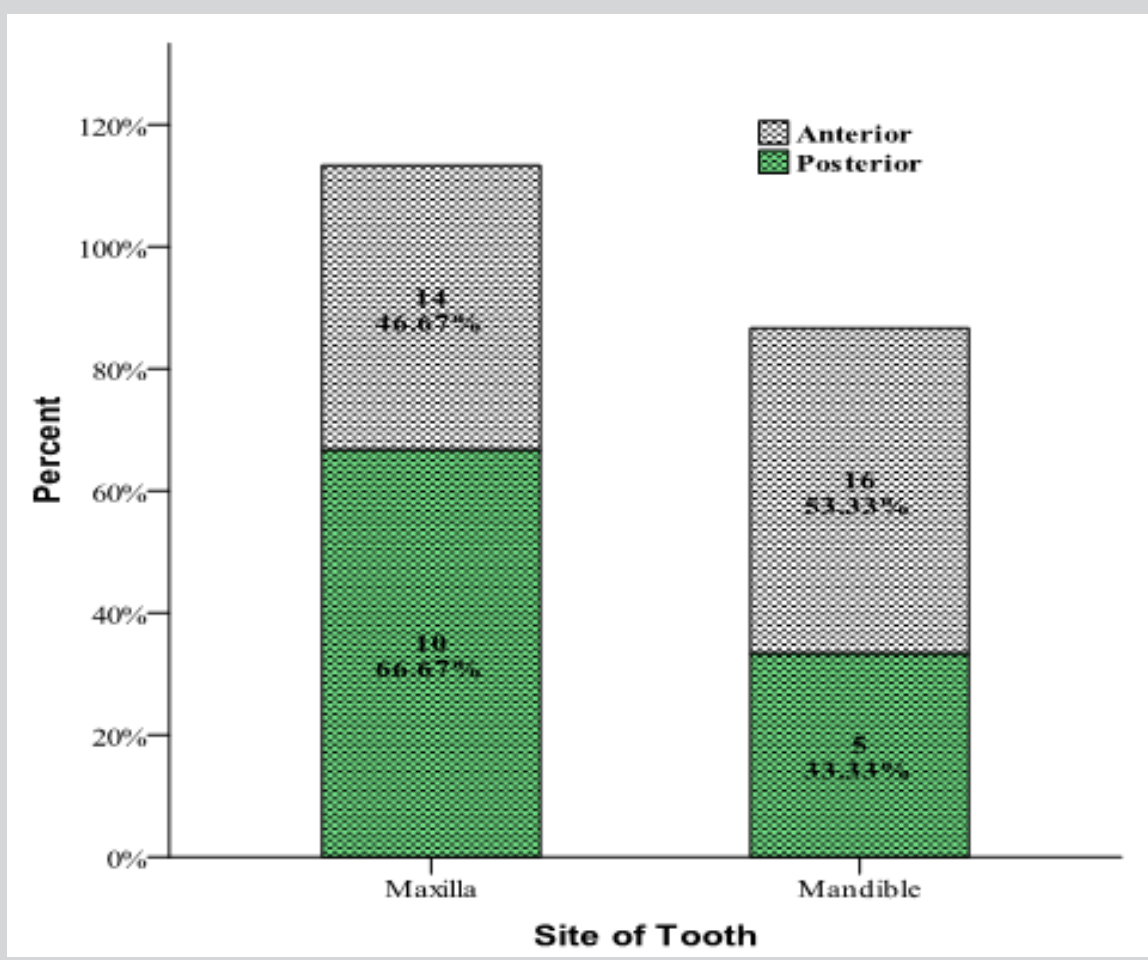

Figure 1: Site of involved tooth. $n=45$ 
Figure 1 shows the involvement of maxilla and mandible in relation with tooth involved. At immediate post-operative, mean defect size was $3.88 \pm 1.25 \mathrm{~cm}$ after $1^{\text {st }}$ week it was observed $3.19 \pm 1.06 \mathrm{~cm}$ than at $4^{\text {th }}$ week follow-up it was $2.46 \pm 0.87 \mathrm{~cm}$ and at $12^{\text {th }}$ weeks defect size was $1.39 \pm 0.61 \mathrm{~cm}$ it was also reduced at $24^{\text {th }}$ week which was observed in $0.53 \pm 0.32 \mathrm{~cm}$. Mean defect size was significantly reduced with respect to follow-up time (Repeated measure ANOVA; within subject effect, $\mathrm{p}=0.0005$ ) (Figure 2).

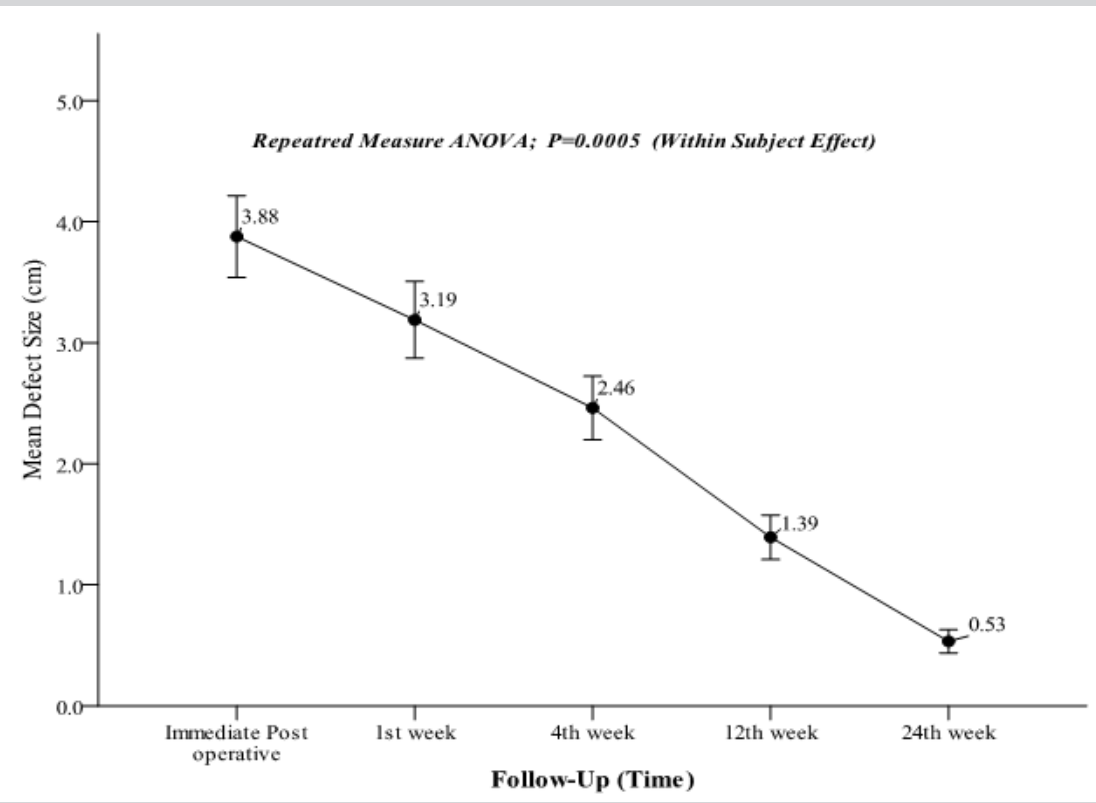

Figure 2: Comparison of mean defect size among follow-up time. $n=45$

Table 3: Comparison of within subject effect of mean defect bone fills.

\begin{tabular}{|c|c|c|c|c|}
\hline \multirow{2}{*}{ Follow-up Time } & \multirow{2}{*}{ Mean Defect Bone Fill \% } & \multirow{2}{*}{ SD } & \multicolumn{2}{|c|}{ 95\% Confidence Interval } \\
\hline & & & Lower Bound & Upper Bound \\
\hline Immediate Post-Operative & 20.66 & 5.61 & 18.979 & 22.354 \\
\hline $1^{\text {st }}$ Week & 36.51 & 4.98 & 35.014 & 38.009 \\
\hline $4^{\text {th }}$ Weeks & 64.71 & 5.5 & 63.059 & 66.364 \\
\hline $12^{\text {th }}$ Weeks & 85.6 & 3.68 & 84.494 & 86.706 \\
\hline $24^{\text {th }}$ Weeks & 95.95 & 1.91 & 95.379 & 96.532 \\
\hline
\end{tabular}

Note: Repeated measure ANOVA applied; $p=0.0005$

Table 4: Pair wise comparison of mean defect bone fills.

\begin{tabular}{|c|c|c|c|c|c|c|}
\hline \multicolumn{2}{|c|}{ Pair } & \multirow{3}{*}{$\begin{array}{c}\begin{array}{c}\text { Mean } \\
\text { Difference }\end{array} \\
15.85^{*}\end{array}$} & \multirow{3}{*}{$\begin{array}{c}\text { Std. Error } \\
0.89\end{array}$} & \multirow{3}{*}{$\begin{array}{c}\text { P-Value. }{ }^{\text {[a] }} \\
0.0005\end{array}$} & \multicolumn{2}{|c|}{$\begin{array}{l}\text { 95\% Confidence Interval for } \\
\text { Difference }\end{array}$} \\
\hline & & & & & \multirow{2}{*}{$\begin{array}{c}\text { Lower Bound } \\
13.18\end{array}$} & \multirow{2}{*}{$\begin{array}{c}\text { Upper Bound } \\
18.5\end{array}$} \\
\hline \multirow{4}{*}{$\begin{array}{l}\text { Immediate post- } \\
\text { operative }\end{array}$} & $1^{\text {st }}$ Week & & & & & \\
\hline & $4^{\text {th }}$ Weeks & $44.04^{*}$ & 0.99 & 0.0005 & 41.1 & 46.98 \\
\hline & $12^{\text {th }}$ Weeks & $64.93^{*}$ & 0.96 & 0.0005 & 62.08 & 67.78 \\
\hline & $24^{\text {th }}$ Weeks & $75.29 *$ & 0.82 & 0.0005 & 72.85 & 77.72 \\
\hline \multirow{3}{*}{$1^{\text {st }}$ Week } & $4^{\text {th }}$ Weeks & $28.20^{*}$ & 1.01 & 0.0005 & 25.21 & 31.18 \\
\hline & $12^{\text {th }}$ Weeks & $49.09^{*}$ & 0.83 & 0.0005 & 46.62 & 51.56 \\
\hline & $24^{\text {th }}$ Weeks & $59.44^{*}$ & 0.74 & 0.0005 & 57.23 & 61.65 \\
\hline \multirow{2}{*}{$4^{\text {th }}$ Weeks } & $12^{\text {th }}$ Weeks & $20.89 *$ & 0.97 & 0.0005 & 18.02 & 23.76 \\
\hline & $24^{\text {th }}$ Weeks & $31.24^{*}$ & 0.85 & 0.0005 & 28.72 & 33.77 \\
\hline $12^{\text {th }}$ Weeks & $24^{\text {th }}$ Weeks & $10.36^{*}$ & 0.43 & 0.0005 & 9.09 & 11.62 \\
\hline
\end{tabular}

*. The mean difference is significant at the 05 level.

[a]. Adjustment for multiple comparisons: Bonferroni. 
Comparison of within subject effect of mean defect bone fills in percent was observed and found increase in percent in mean defect done fill with respect to time (Table 3). At 24 weeks mean defect done fill was $95.95 \pm 1.91 \%$ which is showing significant improvement. Similarly, multiple comparison was performed with bonferroni test and observed that each mean pair difference was high significant as shows within (Table 4).

\section{DISCUSSION}

Marx et al. [16] is the first one who suggested usage of Platelet rich plasma as the applicable technique to gain growth factors (GFs) in high concentration. Form getting autologous platelet growth factors (PGFs), especially for platelet derived growth factor (PDGF) and transforming growth factor $ß$ (TGF $ß$ ) from autologous platelet-rich plasma is a unique method and it is essential for bone regeneration [1,14]. Platelet rich plasma might remain a blood byproduct initiated by using differential centrifugation, during which platelets are concentrated in a little plasma volume Roussy [2]. It should a benefit to make biological gel that provide containment, stability of clot and perform action like adhesive. It is a simple, lowcost effective procedure and should illustrated good results in rapid bone healing [3].

In this study we used platelet rich plasma (PRP) gel for the management of periapical cystic lesion to enhance the bone rapid bone healing. We found mostly young patients both male and females with periapical cyst as $75 \%$ patients with age group of 20 40 years as mean percentage. in this study of $23 \%$ male $(51.11 \%)$ and female $22 \%$ (48.89\%) with the site of involved maxilla and mandible. In anterior maxilla 14 patients (46.67\%), anterior mandible 16 patients $(53.33 \%)$ and in posterior maxilla 10 patients $(66.67 \%)$ in posterior mandible 5 patients $(53.55 \%)$ patients presented. Comparing with similar studies pain is presented in 24 patients (53.3\%), swelling in 45 patients (100\%). Status of tooth mobility in 22 patients (48.9\%), displacement of adjacent teeth in 11 patients $(24.4 \%)$, pus discharge in 6 patients $(13.3 \%)$, colour of aspirated fluid: straw colour is present in 20 patients $(44.4 \%)$ yellow colour in 19 patients $(42.2 \%)$ and transparent colour fluid in patients $6(13.3 \%)$ is presented. Patients with periapical cyst were treated with plasma-rich-plasma gel to fill the bony defect of periapical cystic cavity. Postoperatively, the patients were followed regularly with post-operative radiographic evaluation to observe new bone growth at $1^{\text {st }}, 3^{\text {rd }}$ and $6^{\text {th }}$ month clinically and radiographically. Faster bone healing was observed in the patients in whom Platelet-rich plasma was used at every follow up. Defects filled with Platelet-rich plasma showed comparatively earlier and faster bone regeneration done by Altaf et al. [1].

\section{CONCLUSION}

Platelet-rich plasma gel is highly effective in cystic bony defect healing that resulting from enucleation of a cyst in the speedy ratio clinically and radiographically, so that healing time of cystic cavity used to be reduced to 3 months rather than 6 months to a year. For achieving periapical regeneration alongside bone healing, it is not being a costly technique and it can be utilized as a part of patient treatment who cannot afford costly regenerative procedures.

\section{REFERENCES}

1. Raval RD, Nyklesh V, Patel HM, Naik PS, Patel PP (2015) Management of infected radicular cyst in maxillary anterior region: a case report. International J Adv Health Sci 11(1): 8-11.
2. Mohanty S, Gulati U, Mediratta A, Ghosh S (2013) Unilocular radiolucencies of anterior mandible in young patients: retrospective study. Natl J Maxillofac Surg 4(1): 66-72.

3. Shear M, Speight $P$ (2007) Cyst of the oral and maxillofacial regions, $4^{\text {th }}$ Edn, Oxford: wiley-blackwell, UK, 123-142.

4. Avril L, Lombardi T, Ailianou A, Burkhardt K, Varoquaux A, et al. (2014) Radiolucent lesions of the mandible: a pattern-based approach to diagnosis. Insights Imaging 5(1): 85-101.

5. Sharma S, Sharma V, Passi D, Srivastava D, Grover S, et al. (2018) Large periapical or cystic lesions in association with roots having open apices managed non-surgically Using 1-step apexification based on plateletrich fibrin matrix and biodentine apical barrier: A Case Series. J Endod 44(1): 179-185.

6. Hiremath H, Motiwala T, Jain P, Kulkarni S (2014) Use of secondgeneration platelet concentrate (platelet-rich fibrin) and hydroxyapatite in the management of large periapical inflammatory lesion: a computed tomography scan analysis. Indian J Dent Res 25(4): 517-520.

7. Ricucci D, Mannocci F, Ford TRP (2006) A study of periapical lesions correlating the presence of a radiopaque lamina with histological findings. Oral Surg Oral Med Oral Pathol Oral Endod 101: 389.

8. Suhail L, Shah A, Jan S (2009) Radicular cyst. J Med Edu Reas 11: 187189.

9. Narula H, Ahuja B, Yeluri R, Baliga S, Munshi AK (2011) Conservative non-surgical management of an infected radicular cyst. Contemp Clin Dent 2: 368-371.

10. Joshi N, Sujan S, Rachappa M (2011) An unusual case report of bilateral mandibular radicular cysts. Contemp Clin Dent 2(1): 59-62.

11. Bava FA, Umar D, Bahseer B, Baroudi K (2015) Bilateral radicular cyst in mandible: an unusual case report. J Int Oral Health 7(2): 61-63.

12. You MS, Kim DY, Ahn KM (2017) Surgical management of idiopathic bone cavity: case series of consecutive 27 patients. J Korean Assoc Oral Maxillofac Surg 43(2): 94-99.

13. Kadam NS, Ataide Ide N, Raghava P, Fernandes M, Hede R (2014) Management of large radicular cyst by conservative surgical approach: a case report. J Clin Diagn Res 8(2): 239-241.

14. Dutta SR, Punga R, Varghese D, Bhalodia M (2013) Surgical management of radicular cyst associated with maxillary central incisior. Dent Impact 5: 58-61.

15. Gawai KT, Sobhana CR (2015) Clinical evaluation of use of platelet rich plasma in bone healing. J Maxillofac Oral Surg 14(1): 67-80.

16. Marx RE (2001) Platelet-rich plasma (PRP): what is PRP and what is not PRP? Implant Dent 10(4): 225-228.

17. Zhao JH, Tsai CH, Chang YC (2014) Management of radicular cysts using platelet-rich fibrin and bioactive glass: A report of two cases. J Formosan Med Assoc 113: 470-76.

18. Fernandes G, Yang S (2016) Application of platelet-rich plasma with stem cells in bone and periodontal tissue engineering. Bone Res 13(4): 16036.

19. Subramaniam P, Kumar K, Ramakrishna T, Bhadranna A (2013) Bone regeneration with plasma-rich-protein following enucleation of traumatic bone cyst. Eur J Dent 7: 377-381.

20. Dunfee BL, Sakai O, Pistey R, Gohel A (2006) Radiologic and pathologic characteristics of benign and malignant lesions of the mandible. Radiographics 26(6): 1751-1768.

21. Soffer E, Ouhayoun JP, Anagnostou F (2003) Fibrin sealants and platelet preparations in bone and periodontal healing. Oral Surg Oral Med Oral Pathol Oral Radiol Endod 95: 521-528.

22. Choukroun J, Adda F, Schoeffler C, Vervelle A (2001) Une opportunité en paro-implantologie: le PRF. Implantodontie 42: 55-62. 